\title{
Inhibition of dioxin effects on bone formation in vitro by a newly described aryl hydrocarbon receptor antagonist, resveratrol
}

\author{
S U N Singh ${ }^{1,2}$, R F Casper ${ }^{3,4}$, P C Fritz ${ }^{1,2}$, B Sukhu', ${ }^{2,5}$ B Ganss ${ }^{2}$, \\ B Girard Jr ${ }^{1,2}$, J F Savouret ${ }^{7}$ and H C Tenenbaum ${ }^{1,2,4,5,6}$ \\ ${ }^{1}$ Periodontology Program, Faculty of Dentistry, University of Toronto, Toronto, Ontario, Canada \\ ${ }^{2}$ Medical Research Council Group in Periodontal Physiology, University of Toronto, Toronto, Ontario, Canada \\ ${ }^{3}$ Division of Reproductive Sciences, Department of Obstetrics and Gynecology, Faculty of Medicine, University of Toronto, Toronto, Ontario, Canada \\ ${ }^{4}$ Samuel Lunenfeld Research Institute, Mount Sinai Hospital, Toronto, Ontario, Canada \\ ${ }^{5}$ Departments of Pathology and Laboratory Medicine, Mount Sinai Hospital, Toronto, Ontario, Canada \\ ${ }^{6}$ Department of Dentistry, Mount Sinai Hospital, Toronto, Ontario, Canada \\ ${ }^{7}$ Institut National de la Santé et de la Recherche Médicale, Hôpital de Bicêtre, Le Kremlin-Bicêtre, France \\ (Requests for offprints should be addressed to H C Tenenbaum, Faculty of Dentistry, University of Toronto, 124 Edward Street, Toronto, Ontario, \\ Canada M5G 1G6; Email: howard.tenenbaum@utoronto.ca)
}

\begin{abstract}
Aryl hydrocarbon receptor (AhR) ligands are environmental contaminants found in cigarette smoke and other sources of air pollution. The prototypical compound is TCDD (2,3,7,8-tetrachlorodibenzo-p-dioxin), also known as dioxin. There is an increasing body of knowledge linking cigarette smoking to osteoporosis and periodontal disease, but the direct effects of smokeassociated aryl hydrocarbons on bone are not well understood. Through the use of resveratrol $\left(3,5,4^{\prime}-\right.$ trihydroxystilbene), a plant antifungal compound that we have recently demonstrated to be a pure $\mathrm{AhR}$ antagonist, we have investigated the effects of TCDD on osteogenesis. It was postulated that TCDD would inhibit osteogenesis in bone-forming cultures and that this inhibition would be antagonized by resveratrol. We employed the chicken periosteal osteogenesis (CPO) model, which has been shown to form bone in vitro in a pattern morphologically and biochemically similar to that seen in vivo, as well as a rat stromal cell bone nodule formation model. In the CPO model, alkaline phosphatase (AP) activity was reduced by up to $50 \%(P<0 \cdot 01 \mathrm{vs}$ control $)$ in the presence of $10^{-9} \mathrm{M}$ TCDD and these effects were reversed by $10^{-6} \mathrm{M}$ resveratrol $(P<0 \cdot 05$ vs TCDD alone). TCDD-mediated inhibition of osteogenesis was restricted primarily to the
\end{abstract}

osteoblastic differentiation phase (days 0-2) as later addition did not appear to have any effects. Message levels for important bone-associated proteins (in the CPO model) such as collagen type I, osteopontin, bone sialoprotein and AP were inhibited by TCDD, an effect that was antagonized by resveratrol. Similar findings were obtained using the rat stromal bone cell line. TCDD (at concentrations as low as $10^{-10} \mathrm{M}$ ) caused an approximately $33 \%$ reduction in AP activity, which was abrogated by $3.5 \times 10^{-7} \mathrm{M}$ resveratrol. TCDD also induced a marked reduction in mineralization $(\sim 75 \%)$ which was completely antagonized by resveratrol. These data suggest that AhR ligands inhibit osteogenesis probably through inhibition of osteodifferentiation and that this effect can be antagonized by resveratrol. Since high levels of AhR ligands are found in cigarette smoke, and further since smoking is an important risk factor in both osteoporosis and periodontal disease, it may be postulated that $\mathrm{AhR}$ ligands are the component of cigarette smoke linking smoking to osteoporosis and periodontal disease. If so, resveratrol could prove to be a promising preventive or therapeutic agent for smoking-related bone loss.

Journal of Endocrinology (2000) 167, 183-195

\section{Introduction}

Cigarette smoking is an important risk factor for osteopenia in men (Hollenbach et al. 1993, Nguyen et al. 1994, Egger et al. 1996, Kiel et al. 1996, Grisso et al. 1997) and women (Hopper \& Seeman 1994, Egger et al. 1996, Franceschi et al. 1996). Further, a dose-response relation- ship between the number of cigarettes smoked per day and decreased bone mineral density has been identified (Hollenbach et al. 1993, Franceschi et al. 1996), as has an association between smoking and increased fracture risk (Williams et al. 1982, Aloia et al. 1985, La Vecchia et al. 1991, Hollenbach et al. 1993, Johansson \& Mellstrom 1996, Grisso et al. 1997). 
Similarly, smoking is accepted as one of the stronger risk factors for periodontal disease (Genco \& Kinane 1999), a condition that is characterized by the loss of alveolar bone. Cross-sectional and longitudinal studies have detailed the consistent, positive association between smoking and periodontal attachment loss (Bergstrom 1989, Preber \& Bergstrom 1990, Haber \& Kent 1992, Horning et al. 1992, Haber et al. 1993, Ah et al. 1994). A meta-analysis of the literature conducted by Papapanou (1996) for the 1996 World Workshop in Periodontics revealed that smokers have an almost 3-fold increase in their risk for severe periodontal disease vs non-smokers. Evidence also indicates that failures of endosseous dental implants (relating to osseointegration) are increased in smokers vs non-smokers (Bain \& Moy 1993, De Bruyn \& Collaert 1994).

\section{Potential role for aryl hydrocarbons on bone}

Among products of cigarette smoke which warrant particular attention with respect to bone metabolism, are the aryl hydrocarbon receptor (AhR) ligands. AhR ligands such as dioxin (2,3,7,8-tetrachlorodibenzo-p-dioxin (TCDD)), benzo-a-pyrene (BaP) and polychlorinated biphenyls are environmental contaminants that bind to the AhR, which is present in the cytosol of mammalian cells of almost all organs and tissues. The presence of these detrimental compounds (i.e. $\mathrm{BaP}$ ) in cigarette smoke, combined with the confirmed association between smoking and bone loss, establishes AhR ligands as prime candidates for investigation.

While few studies have been undertaken to investigate the possible direct effects of AhR ligands on bone, it has been shown that during embryonic development of bone tissue in mice both $\mathrm{AhR}$ and $\mathrm{AhR}$ nuclear translocator are expressed (Abbott \& Probst 1995) and that TCDD suppresses differentiation of rat osteoblasts in vitro (Gierthy et al. 1994). This latter study showed that upregulation of alkaline phosphatase (AP) and osteocalcin message was inhibited in calvarial-derived osteoblasts exposed to TCDD. The authors suggested, appropriately, that TCDD-mediated inhibition of the formation of bone tissue-like multicellular nodules in vitro intimates a direct association between TCDD and reduced bone mass in vivo. AhR ligands are known to increase the expression of interleukin-1 $\beta$ in rat liver keratinocytes (Sutter et al. 1991) and the endometrial cell line RL95-2 (Charles \& Shiverick 1997), which could also have a negative impact on bone formation or metabolism.

In light of the above, TCDD or similar AhR ligands could prove to be among the most important compounds linking cigarette smoking to bone loss. In relation to this, we, and others (Ciolino et al. 1998, Casper et al. 1999), have shown that resveratrol $\left(3,5,4^{\prime}\right.$-trihydroxystilbene) is an AhR antagonist and may actually inhibit TCDD effects on cells. This antifungal compound, which is found in high levels in red wine, has been demonstrated to inhibit
TCDD-mediated upregulation of gene transcription dependent on a dioxin response element (Casper et al. 1999).

In view of the foregoing, the goals of this investigation were two-fold. First, we wanted to investigate in more detail how the prototypical AhR ligand, TCDD, might affect bone cell differentiation and bone formation in vitro using previously characterized osteogenic model systems (Maniatopoulos et al. 1988, Tenenbaum et al. 1995, Sukhu et al. 1997, S Kotev-Emeth, S Pitaru, S Pri-Chen \& N Savion, unpublished observations). Secondly, presuming that TCDD did inhibit osteodifferentiation and/or osteogenesis, we also wanted to determine whether these putative effects could be inhibited by resveratrol, thereby 'protecting' bone from the potentially harmful actions of TCDD. Our data suggest that TCDD does inhibit osteodifferentiation, that resveratrol inhibits these effects and that these regulatory events are mediated through the $\mathrm{AhR}$ in bone cells.

\section{Materials and Methods}

\section{Rationale for use of proposed in vitro models}

In order to address the objectives outlined above, we chose to utilize two different models of osteogenesis, the chick periosteal osteogenesis (CPO) model and the stromal bone marrow cell (SBMC) (courtesy of Dr S Pitaru, Tel Aviv University, Israel) model (Pitaru et al. 1993, S KotevEmeth, S Pitaru, S Pri-Chen \& N Savion, unpublished observations). The CPO model has been described in detail previously (Nijweide 1975, Tenenbaum \& Heersche 1982, 1985, 1986, Tenenbaum et al. 1986) and has been shown to produce morphotypical bone reliably within a 6-day culture period. Of course, cell culture systems also have unique advantages that may be exploited as outlined below (Tenenbaum et al. 1986). The SBMC system has also been described in detail (Pitaru et al. 1993, S Kotev-Emeth, S Pitaru, S Pri-Chen \& N Savion, unpublished observations) and is similar to the rat bone marrow cell (RBMC) system (Grigoriadis et al. 1988, Maniatopoulos et al. 1988, Kasugai et al. 1991, McCulloch et al. 1991) in which distinct mineralized bone-like nodules are formed in vitro under appropriate culture conditions. These stable long-term cultures can be analyzed biochemically, and are also adaptable to receptor binding studies, unlike the CPO model. The rationale for using the two systems was that with both, detailed assessment of a much wider variety of outcome measures could be performed than if only one system were used. Moreover, although many findings produced in the CPO model have been replicated in mammalian systems in vitro and in vivo (Tenenbaum 1981, McCulloch \& Tenenbaum 1986, Kamalia et al. 1992, Lekic et al. 1997, Sukhu et al. 1997), it was still thought appropriate to utilize a mammalian model system like the SBMC model. Finally, 
it was thought that if the data produced in both systems were parallel to one another, the validity of those findings would be strengthened and this would reduce the likelihood that the data were related to species or a culture system artifact.

\section{Culture systems}

CPO culture Folded periosteal explants from 17-dayold embryonic chicks were cultured as described previously in detail (Nijweide 1975, Tenenbaum \& Heersche 1982). Media changes occurred on days 2 and 4, and the medium comprised $\mathrm{BGJ}_{\mathrm{b}}$ medium (Fitton-Jackson modification) with L-glutamine (Gibco, Grand Island, NY, USA) and supplemented with 2\% antibiotic (10 000 units/ml penicillin $\mathrm{G}$ sodium, $10000 \mu \mathrm{g} / \mathrm{ml}$ streptomycin sulfate in $0.85 \%$ saline) (Gibco), $10 \%$ fetal calf serum (Gibco), $10^{-7} \mathrm{M}$ dexamethasone (Sigma, St Louis, MO, USA) (Tenenbaum \& Heersche 1985, McCulloch \& Tenenbaum 1986), $10 \mathrm{mM} \quad \beta$-glycerophosphate (Tenenbaum et al. 1989), and $300 \mu \mathrm{g} / \mathrm{ml} \mathrm{L}$-ascorbate (Gibco) (Tenenbaum \& Heersche 1986). The compounds under investigation were added to the media in the appropriate concentrations (see below).

Rat SBMC line culture Cells for the SBMC model were obtained from Dr Sandu Pitaru (Tel Aviv University, Israel) and maintained in $\mathrm{T}_{25}$ tissue culture flasks (Sarstedt, Newton, NC, USA) in a medium composed of MEM+RNA+DNA+antibiotic supplemented with $10 \%$ fetal calf serum, $10 \mathrm{mM} \beta$-glycerophosphate, $10^{-8} \mathrm{M}$ dexamethasone, $50 \mu \mathrm{g} / \mathrm{ml}$ vitamin $\mathrm{C}$ and $3 \mathrm{ng} / \mathrm{ml}$ fibroblast growth factor. The media were changed every $48 \mathrm{~h}$ and the cells subcultured when almost confluent (approximately every $72 \mathrm{~h}$ ). Cells were grown for a period of 1-2 weeks to allow for formation of mineralized bone nodules.

\section{Biochemical analyses}

$\mathrm{CPO}$ and SBMC cultures were assayed for AP activity using paranitrophenol-phosphate $(\mathrm{pN}-\mathrm{p})$ as the substrate (Tenenbaum et al. 1995, Demetriou et al. 1996). The intensity of the color change was evaluated using a Titertek Multiskan MCC/340 Spectrophotometer (Flow Laboratories, Mississauga, ON, Canada) and compared with a standard curve obtained from a serial dilution of $10 \mathrm{mM}$ pN with bicarbonate buffer $(\mathrm{pH} 7 \cdot 4)$ in flat bottomed Titertek 96-well plates as described previously (Demetriou et al. 1996). Calcium incorporation was assayed in the pellets produced from centrifugation of the homogenized CPO cultures following hydrolysis in $500 \mu \mathrm{l}$ $0.5 \mathrm{M} \mathrm{HCl}$ and then measured using atomic absorption spectrophotometry (Sukhu et al. 1997). In some cases, AP activity was also measured using direct staining in situ of SBMC cultures in 96-well plates as described previously (Tenenbaum et al. 1995, Demetriou et al. 1996). Miner- alization in the SBMC cultures was determined using Alizarin Red staining also in situ, which was assessed with the Titertek spectrophotometer set at $525 \mathrm{~nm}$. In the case of direct in situ staining, only relative units were used based on 'zeroing' the Titertek spectrophotometer with empty wells.

Radiolabeled collagen was measured in CPO cultures incubated with $\left[{ }^{14} \mathrm{C}\right]$ glycine (Amersham Pharmacia Biotech Inc., Quebec City, Canada, $59 \mathrm{mCi} / \mathrm{mmol}$ ) at a concentration of $10 \mu \mathrm{Ci} / \mathrm{ml}$ media in each group over days 4-6 as described previously (Tenenbaum et al. 1995). Fluorography was used to analyze the amount of newly synthesized ${ }^{14} \mathrm{C}$-labeled collagen in each sample. The intensity of the resultant bands on the film was quantified using a laser densitometer to give a measure of the amount of newly synthesized collagen in each sample.

\section{Competitive binding assay for TCDD and resveratrol}

Four replicates were used in conducting the live wholecell competition binding assay to demonstrate specific receptor-mediated uptake of radiolabeled TCDD. This technique has been described previously (Tenenbaum et al. 1995, Sukhu et al. 1997) and demonstrates results that are comparable to more traditional binding assays relying on cytosol preparations. However, it should be pointed out that the binding curves produced using vital cell assays may be different from those produced using more standard cytosol binding assays. Thus, it is not possible to calculate $K_{\mathrm{d}}$ in these studies. However, this vital cell uptake/ binding can be accomplished with far fewer cells than would otherwise be required to generate appropriate amounts of cytosol for more conventional assays. Cells were plated at a density of 10000 per well in Titertek 96-well plates, and left overnight to attach in medium. The medium was removed by aspiration and the various concentrations of 'cold' drug (TCDD, resveratrol) were prepared and added to the wells in a volume of $90 \mu$ l. Cells were preincubated with cold drug $1 \mathrm{~h}$ prior to addition of radiolabeled TCDD (specific activity $33.4 \mathrm{Ci} / \mathrm{mmol}$; Chemsyn Lab., Lenexa, KS, USA), pilot studies having shown that preincubation was required to detect competition. One set of wells was incubated without cold drug to determine total binding. $\left[{ }^{3} \mathrm{H}\right] \mathrm{TCDD}$ (10 000 c.p.m./well in a volume of $10 \mu \mathrm{l}$ ) was added and incubated for $4 \mathrm{~h}$ at room temperature. The media were aspirated and the cells washed four times with $100 \mu \mathrm{l}$ PBS. One hundred microliters of $0.05 \mathrm{M}$ sulfuric acid were added and the cells were incubated at $37{ }^{\circ} \mathrm{C}$ overnight to break the cells open. Eighty microliters of the lysate were added to $5 \mathrm{ml}$ of scintillation fluid and ${ }^{3} \mathrm{H}$ counted in a beta counter.

\section{Semiquantitative RT-PCR}

The isolation of total RNA from periosteal cultures was accomplished using the QIAGEN RNeasy kit and 
QIAShredder (Hilden, Germany) according to the manufacturer's instructions. Total RNA $(2 \mu \mathrm{g})$ was reverse transcribed using SuperScript II RNase $\mathrm{H}^{-}$Reverse Transcriptase (Gibco BRL). PCR reactions were performed in $20 \mu \mathrm{l}$ volumes at a cycle number ensuring a linear amplification profile (bone sialoprotein (BSP), $5 \mathrm{~min}$ at $94{ }^{\circ} \mathrm{C}, 30$ cycles of $20 \mathrm{~s}$ at $94{ }^{\circ} \mathrm{C}, 20 \mathrm{~s}$ at $55^{\circ} \mathrm{C}, 20 \mathrm{~s}$ at $72{ }^{\circ} \mathrm{C}$; collagen 5 min at $94^{\circ} \mathrm{C}, 30$ cycles of $20 \mathrm{~s}$ at $94^{\circ} \mathrm{C}$, $20 \mathrm{~s}$ at $58^{\circ} \mathrm{C}, 20 \mathrm{~s}$ at $72{ }^{\circ} \mathrm{C}$; AP 5 min at $94{ }^{\circ} \mathrm{C}, 30$ cycles of $20 \mathrm{~s}$ at $94^{\circ} \mathrm{C}, 20 \mathrm{~s}$ at $59^{\circ} \mathrm{C}, 20 \mathrm{~s}$ at $72^{\circ} \mathrm{C}$; osteopontin (OPN) 5 min at $85^{\circ} \mathrm{C}, 5 \mathrm{~min}$ at $94^{\circ} \mathrm{C}, 25$ cycles of $20 \mathrm{~s}$ at $94{ }^{\circ} \mathrm{C}, 20 \mathrm{~s}$ at $60{ }^{\circ} \mathrm{C}, 20 \mathrm{~s}$ at $72{ }^{\circ} \mathrm{C}$, and $7 \mathrm{~min}$ at $\left.72{ }^{\circ} \mathrm{C}\right)$. The oligonucleotides for BSP (sense: $5^{\prime}$-GAGCGGGCAC CGGTACTA-3'; antisense: 5'-CTCTAGACACTGA CATCCTGCTC-3'), AP (sense: $5^{\prime}$-ACCGCTGCAAC ACCACCA-3'; antisense: 5'-TCCCCGCAGGCTTA GTGT-3'), collagen (sense: 5'-ACCCGACCCTAAGA

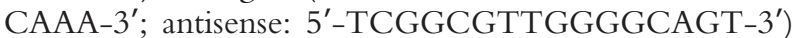
and OPN (sense 5'-AGGCCGGGGTGACAGTGT-3'; antisense 5'-CCCCGCAGGCAGCACTC-3') were synthesized by Life Technologies (Gibco BRL, Rockville, MD, USA).

PCR products were electrophoresed on $1.5 \%(\mathrm{w} / \mathrm{v})$ agarose gels with $0 \cdot 1 \mu \mathrm{g} / \mathrm{ml}$ ethidium bromide. The gels were visualized on a UV transilluminator and photographed using 667 Polaroid film. The inverse images of the photographs were analyzed by densitometry. All values were normalized for the internal control, $\beta$-actin.

\section{Temporal experimental conditions in the CPO model}

As alluded to above, the CPO model traverses a number of phases of osteogenesis. Therefore, it was possible to design temporal or 'window' experiments in order to determine the phases of osteogenesis that were sensitive to TCDD and/or resveratrol. CPO cultures were treated with TCDD $10^{-9} \mathrm{M}$, resveratrol $10^{-6} \mathrm{M}$, TCDD $10^{-9} \mathrm{M}$ or vehicle. All cultures were maintained for the entire 6-day period. The compounds were administered over four different temporal phases, i.e. days $0-6$; days $0-2$; days $2-4$ or days 4-6. (All cultures were stopped at 6 days.) Results were compared with vehicle alone over days 0-6.

The cultures received vehicle control when not receiving resveratrol or TCDD and the media were changed every $48 \mathrm{~h}$. When given together, TCDD and resveratrol were added simultaneously to assess their effects in direct combination.

\section{Statistical methods}

All CPO experiments were carried out with nine cultures per group except for the mRNA extraction in which 12 cultures per group were utilized. The rat SBMC line experiments were carried out with three replicates per group in all cases. In all experiments the results from each treatment group were compared only against the group which received vehicle-containing media (denoted as 'vehicle' in the figures). In the RT-PCR experiments, multiple comparisons between groups were performed using one-way ANOVA, and Student-Newman-Keul's test for post-hoc analysis.

\section{Results}

\section{Bone formation in the CPO model}

As shown in Fig. 1, there were obvious changes in bone formation in CPO cultures treated with TCDD. Although morphometric measurements were not made, the TCDDtreated specimens (Fig. 1B) had to be sectioned completely to visualize any bone at all. In those cultures, however, the small amount of bone that did form appeared to be more or less normal in that there was recognizable bone matrix containing osteocytic cells that was also surrounded by osteoblast-like cells. There appeared to be a complete reversal of the TCDD effect in cultures treated with both TCDD and resveratrol (Fig. 1D). Large seams of bone were visualized readily and the bone, which was surrounded by a multilayer of osteoblasts, contained numerous osteocytes. The cultures treated with both TCDD and resveratrol were indistinguishable from control cultures (Fig. 1A) or cultures treated with resveratrol alone (Fig. 1C), which also demonstrated large deposits of bone.

\section{Biochemical markers of osteogenesis in the CPO model}

Cultures treated with $10^{-9} \mathrm{M}$ TCDD over a 6-day period showed $80 \%$ reduction in AP activity vs cultures with vehicle alone. Resveratrol, at doses of $10^{-5} \mathrm{M}, 10^{-6} \mathrm{M}$ and $10^{-7} \mathrm{M}$ partially prevented TCDD's inhibitory effects by increasing AP activity 2 - to 4 -fold in comparison to TCDD alone (Fig. 2a). Administration of $10^{-9} \mathrm{M}$ TCDD alone during days $2-4$ or $4-6$ did not significantly alter AP activity, but administration during days 0-2 reduced AP activity by $53 \%$, similar to that of 6-day treatment $(P<0.05$ vs vehicle) (Fig. $2 b)$. No significant change in AP activity was noted when $10^{-6} \mathrm{M}$ resveratrol alone was added over days $0-6$, days $0-2$, days $2-4$, or days 4-6 (Fig. 2c). As shown in Fig. 3, message levels for AP were also reduced about $50 \%(P<0 \cdot 05)$ in cultures treated with TCDD in comparison with control. In cultures treated with both TCDD and resveratrol, the mRNA levels were similar to those in control. In parallel with AP, mRNA levels for OPN were reduced by about $40 \%$ $(P<0 \cdot 05)$ in the presence of TCDD and restored in cultures treated with both TCDD and resveratrol. A similar profile was demonstrated for BSP in that there was about a 4-fold reduction in mRNA for BSP in the presence of TCDD $(P<0 \cdot 05)$ as shown in Fig. 3. This inhibition was reversed completely with resveratrol. 

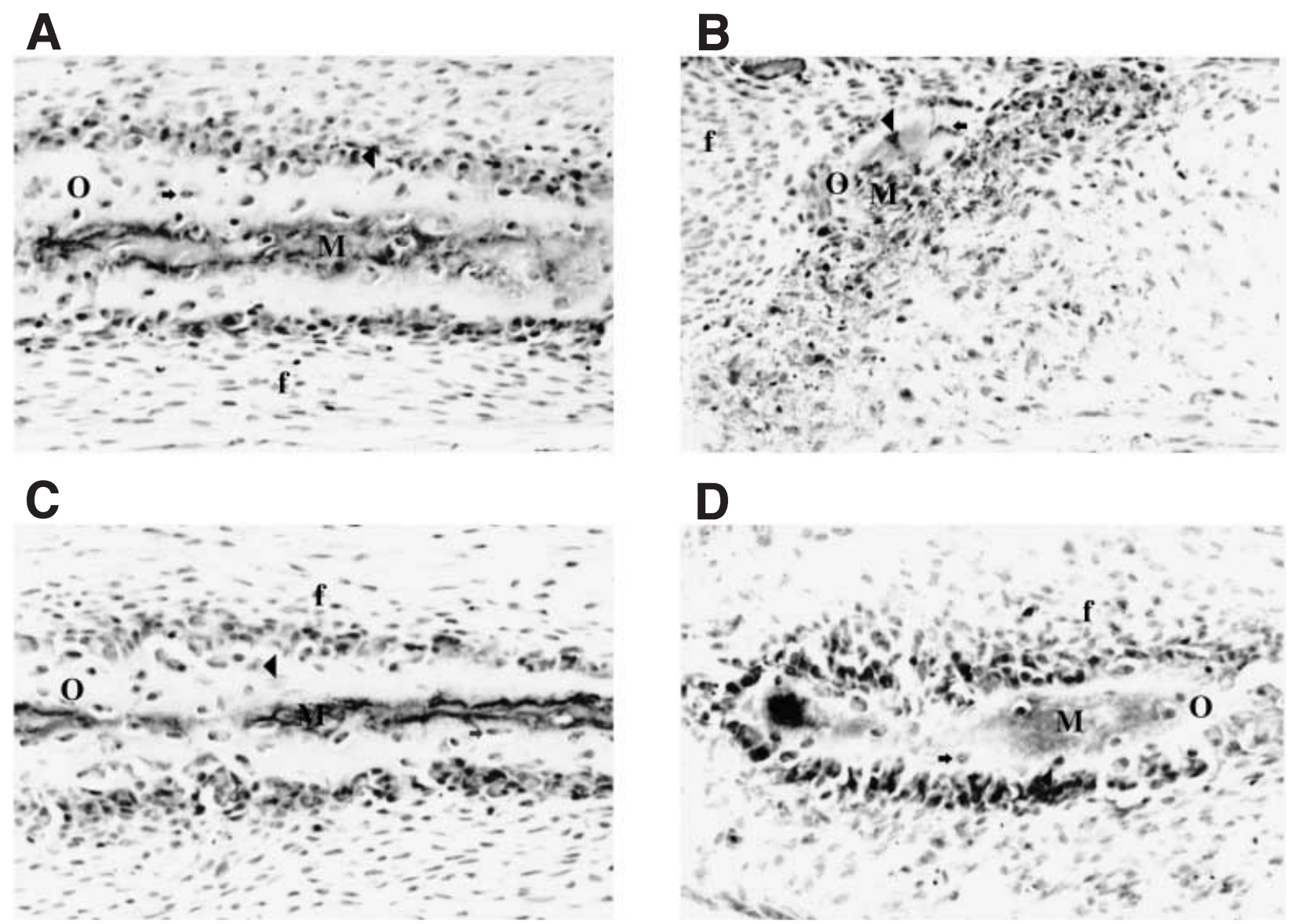

Figure 1 Histological evaluation of $5 \mu \mathrm{m}$ thick paraffin-embedded sections obtained from CPO cultures stained with hematoxylin and eosin. (A) Control cultures treated with vehicle only contained easily recognizable seams of mineralized bone (M) surrounded by unmineralized osteoid $(\mathrm{O})$. The layer of bone is surrounded by a multilayer of osteoblasts (arrowhead) and contains numerous osteocytes (small arrow). The bone seam and osteoblasts are surrounded by a collagen-rich layer of fibrous periosteum (f). (B) In TCDD-treated cultures $\left(10^{-9} \mathrm{M}\right)$, there were only small islands of bone. In fact, the TCDD-treated cultures had to be sectioned completely through to visualize any bone (if it was present at all). Otherwise, the appearance of the bone in both other groups (C, D) was indistinguishable from vehicle-treated control (A) and could be detected early on and throughout the sectioning process. Original magnification in all sections: $480 \times$.

Interestingly, resveratrol alone appeared to partially downregulate message for collagen and BSP but not other transcripts.

\section{Matrix synthesis in the CPO model}

Newly synthesized collagen type I levels (reported as absorbance units $(\mathrm{AU}) \times \mathrm{mm}$ ) were decreased by about $30 \%$ in the treatment groups receiving $10^{-9} \mathrm{M}$ TCDD alone $(P>0 \cdot 05)$, while $10^{-6} \mathrm{M}$ resveratrol alone had no effect compared with vehicle (Fig. 4). Co-treatment with TCDD and resveratrol increased the newly synthesized collagen type I level (Fig. 4a), but this was not significantly different from the collagen levels shown for cultures treated with TCDD alone. However, as shown in Fig. 3, mRNA levels for type I collagen were reduced signifi- cantly $(50 \%, P<0 \cdot 05)$ in the presence of TCDD in comparison to control, while cultures treated with both TCDD and resveratrol had identical levels of mRNA for type I collagen.

\section{SBMC line}

AP As shown in Fig. 5, TCDD $\left(3.3 \times 10^{-9} \mathrm{M}\right.$ and higher) induced a 33\% reduction in AP activity vs control but this reduction was not reversed by administration of resveratrol at various concentrations, suggesting that the TCDD levels were probably too high to be attenuated with resveratrol doses used. A 33\% reduction in AP activity was also shown following treatment with a lower concentration of TCDD $\left(1.1 \times 10^{-9} \mathrm{M}\right)$. In this case, however, increasing concentrations of resveratrol 


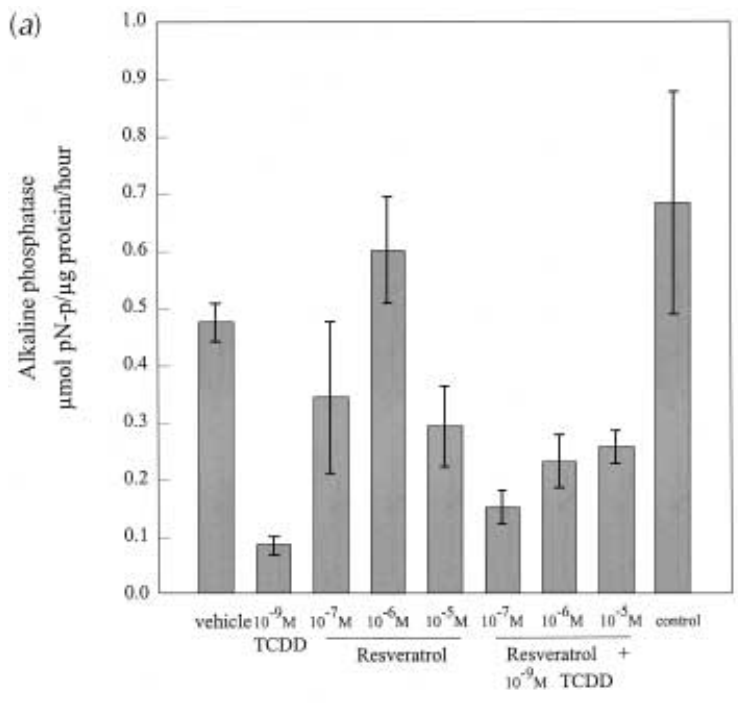

(b)
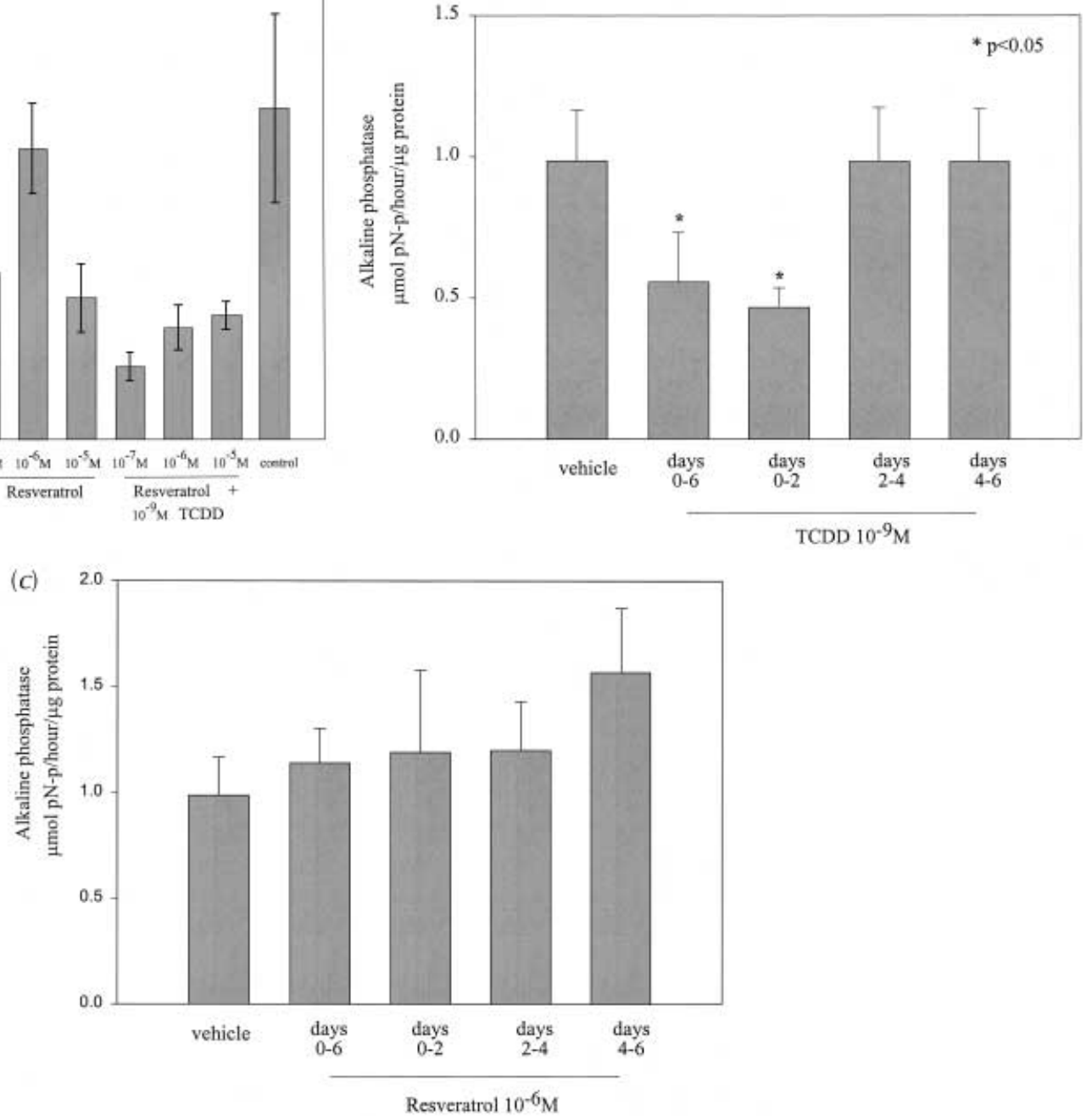

Figure 2 (a) AP activity in 6-day CPO cultures was reduced dramatically $(P<0 \cdot 05)$ with TCDD $\left(10^{-9} \mathrm{M}\right)$ treatment in comparison to complete control (nothing added to medium) or vehicle control. AP activity was increased by 2- to 3-fold in cultures treated with both TCDD and resveratrol $\left(10^{-6} \mathrm{M}\right)$ as compared with cultures treated with TCDD alone $(P<0 \cdot 05)$, although in this experiment AP activity was not totally restored to control levels. (b) TCDD $\left(10^{-9} \mathrm{M}\right)$ had its most profound inhibitory effects on AP activity when CPO cultures were treated either over the entire 6-day culture period or during days 0-2 (differentiation phase). When cultures were treated with TCDD after the differentiation phase, there was little to no inhibitory effect on AP activity. In this series of experiments, AP activity was reduced by only about $50 \%$ in comparison with control, whereas in (a) there appeared to be at least an $80 \%$ reduction. It should be noted that overall AP activity was also different in both experiments. This variation is not unusual for this type of tissue culture system, and so direct statistical comparisons are only made within and never between experiments. Resveratrol alone $\left(10^{-6} \mathrm{M}\right)$ had no major effects on AP activity $(c)$ no matter when it was added. However, there was a mild, but non-significant $(P>0 \cdot 05)$ stimulatory effect on AP activity when resveratrol was added over days $4-6$.

$\left(4 \times 10^{-8} \mathrm{M}\right.$ to $\left.1 \times 10^{-5} \mathrm{M}\right)$ abrogated the effects of TCDD and brought AP activity back to, and even above that seen in control cultures, which is quite different from that observed in the CPO model but nonetheless depicts a parallel trend. This pattern was repeated in the cultures receiving lower levels of TCDD. The initial reduction in AP activity due to TCDD was dose dependent $\left(3 \cdot 3 \times 10^{-9} \mathrm{M}\right.$ to $\left.4 \cdot 12 \times 10^{-11} \mathrm{M}\right)$. The abrogation of the effect of TCDD by increasing resveratrol concentrations was exhibited at each level of TCDD administration until a concentration of $4 \cdot 12 \times 10^{-11} \mathrm{M}$ TCDD was reached. At this concentration, AP activity was not affected (i.e. similar to control) and the increasing concentration of resveratrol had no effect either. At several of the 


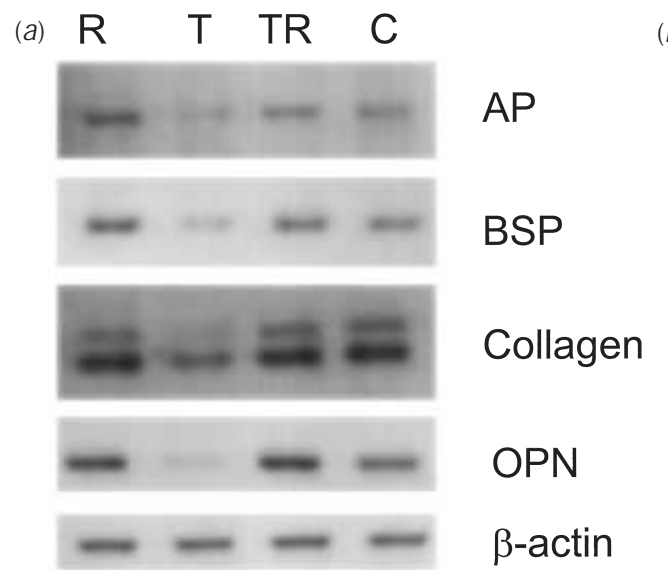

(b)

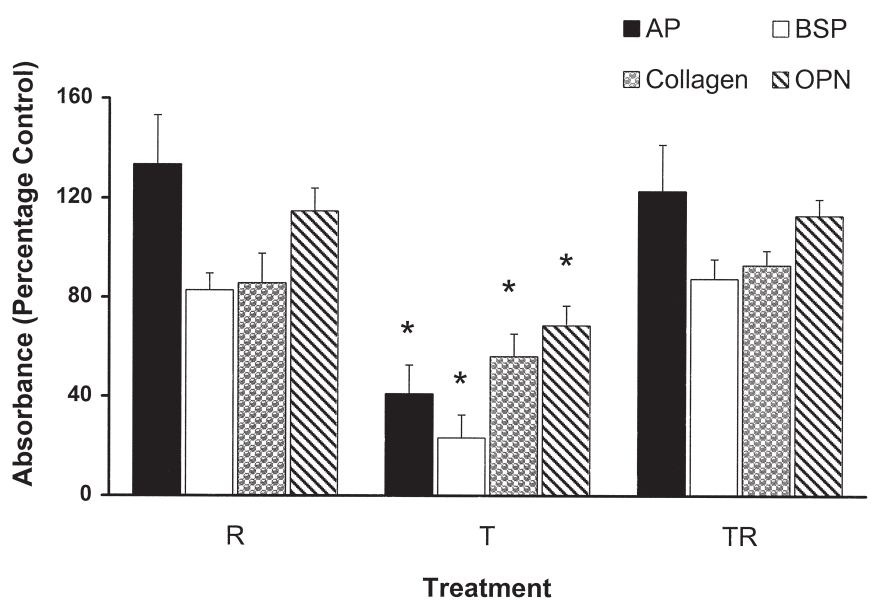

Figure 3 A semiquantitative RT-PCR method was used to demonstrate changes in mRNA expression for bone proteins in CPO cultures treated with TCDD (T) and resveratrol (R). (a) Agarose gel electrophoresis patterns for RT-PCR products demonstrate obvious reductions in mRNA bands for bone proteins, AP, BSP, OPN and collagen in cultures treated with TCDD. Band intensity was increased to control levels in cultures treated with TCDD plus resveratrol (TR). $\beta$-actin bands were consistent in all groups, as would be expected for this 'housekeeping gene'. (b) Band intensities were estimated using densitometric measurements. The numbers are expressed as the means \pm S.E.M. of triplicate measurements. All values were normalized against $\beta$-actin. Statistical significance was set at $P<0.05$ by ANOVA and is denoted on the bars by an asterisk $\left(^{*}\right)$.

lower TCDD concentrations, the addition of the highest levels of resveratrol caused an increase in AP activity above that found in control, suggesting that resveratrol could have its own stimulating effects, or perhaps other cooperative AhR interactions, as will be discussed below.

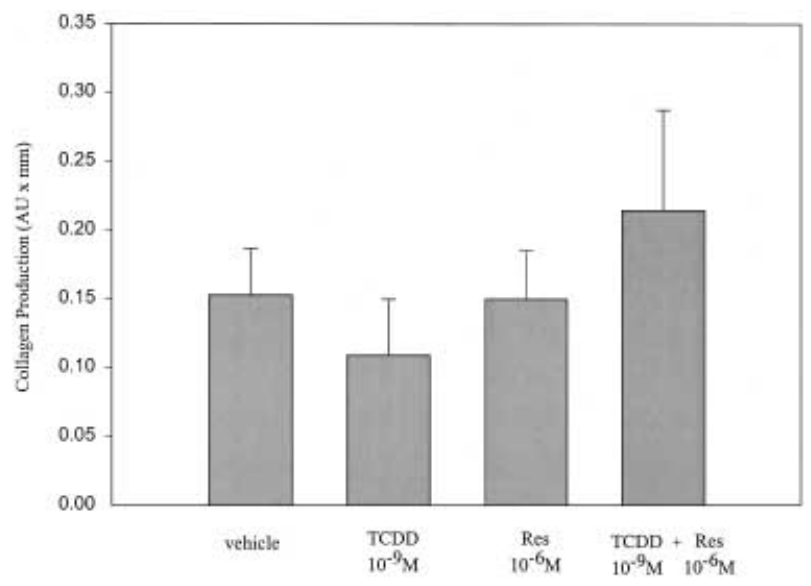

Figure 4 Radiolabeled $\left({ }^{14} \mathrm{C}\right)$ collagen type I levels in 6-day cultures treated with $10^{-9} \mathrm{M}$ TCDD with or without $10^{-6} \mathrm{M}$ resveratrol (Res) co-incubation over the entire culture period. There was a trend suggesting inhibition of newly synthesized collagen in the presence of TCDD, which was reversed by resveratrol. However, these differences were not found to be significantly different despite the obvious changes in bone formation suggested in Fig. 1 and changes in collagen mRNA shown in Fig. 3.
Interestingly, this was also suggested in the $\mathrm{CPO}$ model where mRNA for AP also demonstrated a tendency to be higher than control (see Fig. 3).

Mineralization in the rat SBMC line There was a dose-dependent reduction in mineralization (i.e. Alizarin Red staining) in the presence of $4.12 \times 10^{-11} \mathrm{M}$ to $1.52 \times 10^{-12} \mathrm{M}$ TCDD (Fig. 6). Mineralization was decreased by approximately $75 \%$ in the presence of TCDD, which was attenuated by resveratrol. Interestingly, at the highest concentration of resveratrol, not only were TCDD effects attenuated but there appeared to be a 3 -fold increase relative to control levels, further suggesting a direct stimulatory effect or some form of cooperative interactions between TCDD and resveratrol.

Specific binding of TCDD and resveratrol Increasing concentrations of TCDD effectively competed with $\left[{ }^{3} \mathrm{H}\right] \mathrm{TCDD}$ for its cognate receptor and reduced binding to background levels at $3 \cdot 3 \times 10^{-8} \mathrm{M}$, thus suggesting the existence of the AhR in SBMCs despite the fact that 'classic' competition curves were not demonstrated. Approximately $50 \%$ competition was achieved at $3 \cdot 7 \times$ $10^{-9}$ M TCDD (Fig. 7a). Resveratrol competed with $\left[{ }^{3} \mathrm{H}\right] \mathrm{TCDD}$ in a similar fashion. Resveratrol $(1.37 \times$ $10^{-9} \mathrm{M}$ ) also reduced radiolabeled TCDD binding to background levels, while 50\% competition occurred at $\sim 1.8 \times 10^{-10} \mathrm{M}$ resveratrol, a dose 20 times lower than the dose of unlabeled TCDD required to produce this level of competition (Fig. 7b). 


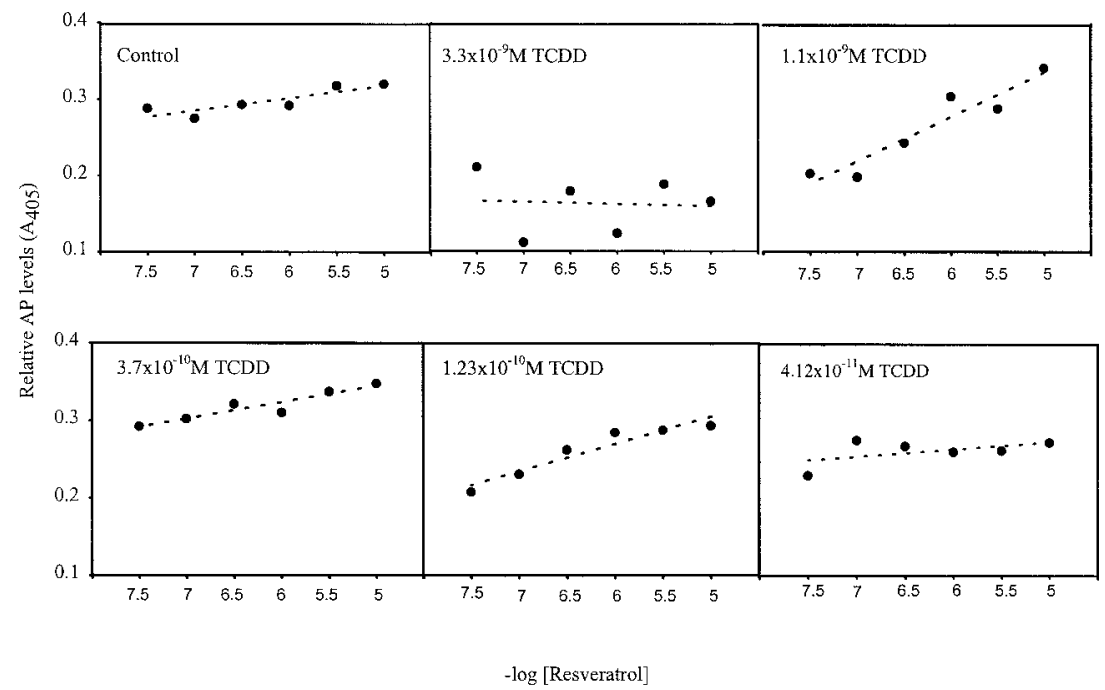

Figure 5 Relative (to blank wells) AP levels in the rat SBMC line. Each panel represents one TCDD concentration (or control as in the first panel) in the presence of increasing levels of resveratrol $\left(4 \times 10^{-8} \mathrm{M}\right.$ to $\left.1 \times 10^{-5} \mathrm{M}\right)$. TCDD appeared to reduce AP levels by up to about $33 \%(P<0 \cdot 05)$, an effect that was antagonized and even stimulated above control by increasing concentrations of resveratrol except at the highest levels of TCDD where resveratrol, even in higher doses, had no antagonistic effect.

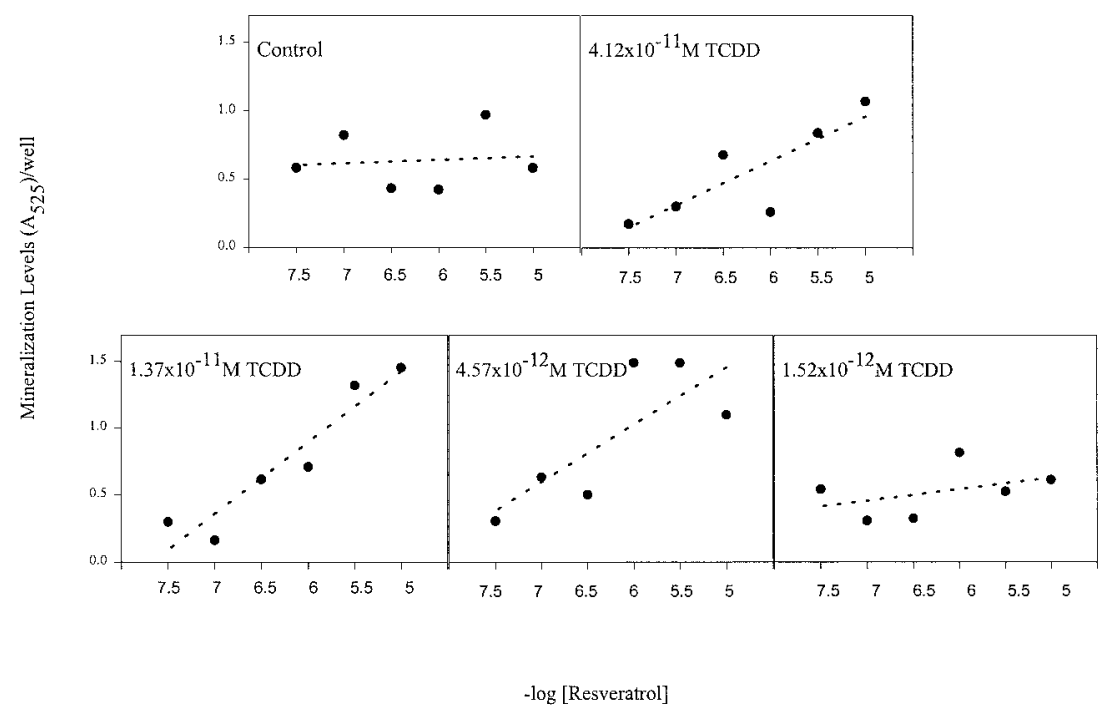

Figure 6 Relative mineralization levels in the rat SBMC line. Each panel represents either control or a single dose of TCDD in the presence of increasing concentrations of resveratrol as outlined in Fig. 5. As shown for AP, TCDD inhibited mineralization (Alizarin Red staining) $(P<0 \cdot 05)$ and this effect was antagonized by increasing doses of resveratrol, which at the highest levels stimulated mineralization above control levels. Relative absorbance refers to absorbance compared with blank wells.

\section{Discussion}

The studies we employed were designed to test the effects of a prototypical AhR ligand, TCDD (Rowlands \& Gustafsson 1997), on bone formation in vitro. Using two different in vitro bone-forming models it was shown that
TCDD inhibits bone formation and that a novel AhR antagonist, resveratrol, partially and in some cases completely reverses this inhibition. The competition studies confirm that these effects are mediated through the AhR as shown in other systems (Birnbaum 1994, Sukhu et al. 1997, Lavin et al. 1998). Currently no endogenous ligand 

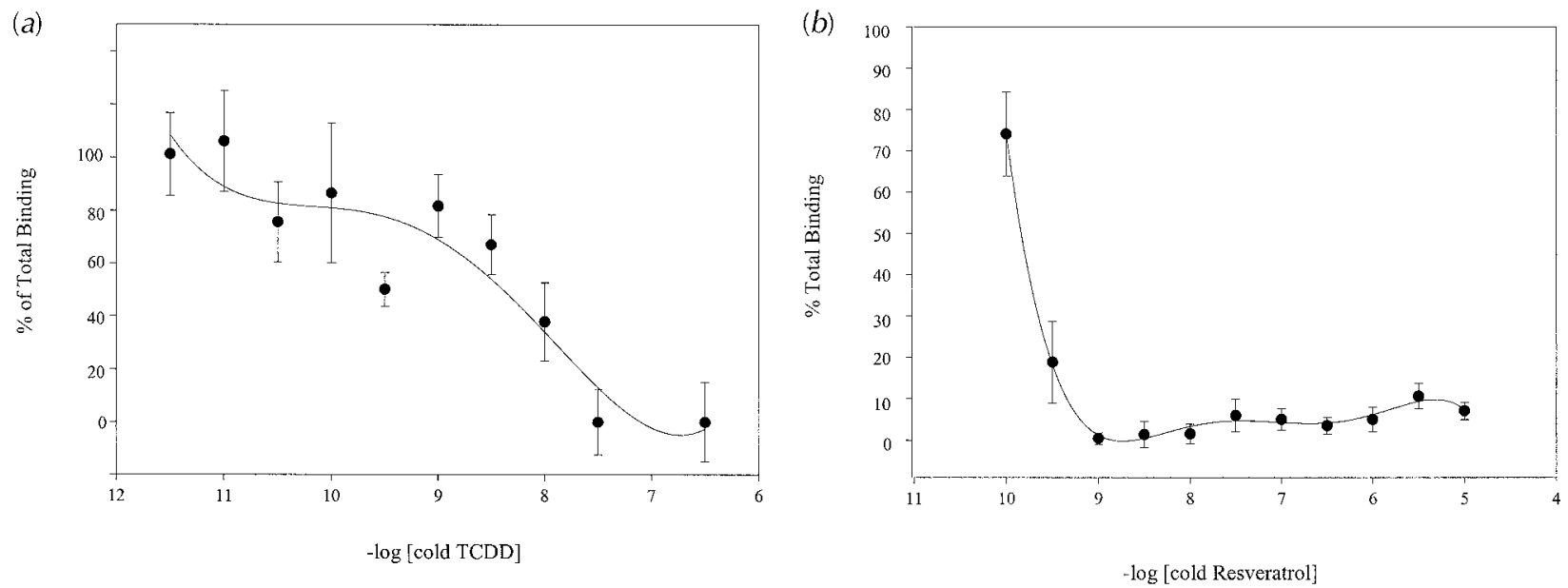

Figure 7 A live cell (SBMC) competition assay demonstrating competitive uptake/binding between radiolabeled TCDD and either unlabelled TCDD (a) or resveratrol (b). Background uptake/binding was subtracted for these calculations. Binding/uptake of radiolabeled TCDD was reduced to background levels at a dose of $3.3 \times 10^{-8} \mathrm{M}$ TCDD and 50\% competition was produced with a dose of approximately $3.7 \times 10^{-9} \mathrm{M}$ TCDD. A dose of $1.37 \times 10^{-9} \mathrm{M}$ resveratrol reduced uptake/binding of radiolabeled TCDD to background levels while $50 \%$ competition occurred at a dose of approximately $1.8 \times 10^{-10} \mathrm{M}$ resveratrol. All cultures were pre-treated for a period of $1 \mathrm{~h}$ with 'cold' TCDD or resveratrol prior to adding the labeled TCDD. Although 'classic' competition curves were not produced in these studies, there was still, nonetheless, clear competitive binding. However, binding kinetics were not calculated as a result.

has been identified for the AhR and the only known natural ligands for this 'orphan receptor' are methyleneindole condensation products formed after ingestion of cruciferous vegetables such as cabbage, broccoli and cauliflower (Bjeldanes et al. 1991). In addition to being linked to the pathoses listed above, TCDD and other AhR ligands may have anti-estrogenic effects as demonstrated by their ability to inhibit a broad spectrum of estrogeninduced responses in rodents and breast cancer cell lines (Harris et al. 1990, Safe et al. 1991, Wang et al. 1993, Gierthy et al. 1994, Harper et al. 1994, Liu et al. 1994, Krishnan et al. 1995, Safe \& Krishnan 1995, Nodland et al. 1997). However, as discussed below, resveratrol might also possess estrogen-like activity, although this is less likely.

\section{Differentiation}

AP activity and OPN Utilizing the CPO model, it was shown that $10^{-9} \mathrm{M}$ TCDD administration over days 0-6 (i.e. the entire culture period) consistently caused a significant reduction in AP activity and transcripts. Similarly, $10^{-6} \mathrm{M}$ resveratrol antagonized the effects of TCDD on AP activity consistently. AP has a number of functions and may act as an inorganic phosphate provider or as a modulator of matrix macromolecule turnover (Golub 1996), as well as in other diverse manners including regulation of mineralization (see below). In any case, synthesis of AP is accepted as a hallmark of the osteoblastic phenotype and bone formation (Termine 1993). The doses of TCDD and resveratrol shown to have a significant effect in the CPO model are consistent with doses used by other investigators employing other systems (Gierthy et al. 1994, Mizutani et al. 1998) and in a breast cancer cell line (Casper et al. 1999). As well, the findings obtained for AP activity using the CPO model were paralleled in the rat SBMC line. However, as will be pointed out below, resveratrol alone may have stimulatory effects on its own or in combination with TCDD. The effects of TCDD on AP activity were dose dependent, and the ability of resveratrol to antagonize these effects was likewise shown to be dose dependent. Given similar findings in the two models it appears that TCDD inhibits osteoblastic AP activity and probably osteodifferentiation, and that resveratrol antagonizes this effect in a manner that is neither species nor model specific. Similar effects were shown with OPN, another marker for osteoblastic differentiation, further suggesting that TCDD inhibits osteodifferentiation. To investigate TCDD (and resveratrol) effects on differentiation further, we also carried out a series of temporal studies.

The temporal or 'window' experiments suggested that TCDD's inhibitory effects on osteodifferentiation, as reflected by AP activity, were exerted mainly during the early osteodifferentiation phase of culture in the CPO model (i.e. over days 0-2). Since TCDD inhibited parameters of osteogenesis when present at days $0-2$, and not when added later, it may be suggested that while this agent interferes with osteoblastic differentiation, it has fewer effects on already differentiated osteoblasts. Consistent with our previous results, resveratrol administration antagonized the effects of TCDD when the two drugs were given together over days $0-2$, confirming resveratrol's ability to reverse the effects of TCDD. 
A second interesting finding in the $\mathrm{CPO}$ temporal studies was a trend suggesting an increase in AP activity induced by administration of resveratrol alone over days 4-6 (Fig. 2c;P>0.05). These data, combined with the finding that resveratrol induces a dose-dependent increase in AP activity and mineralization above control levels in the rat SBMC line, a mature osteoblastic cell line that is capable of producing mineralized bone-like tissue (Pitaru et al. 1993, S Kotev-Emeth, S Pitaru, S Pri-Chen \& N Savion, unpublished observations), intimate a potentially stimulatory effect of this drug on more differentiated osteoblasts. This effect was observed only when resveratrol was administered during the late stages of osteogenesis (i.e. days 4-6 in the CPO model), pointing toward the presence of a resveratrol-responsive cell population that is more fully differentiated (Tenenbaum 1981, Tenenbaum \& Heersche 1982, 1985). This phenomenon has recently been observed and reported elsewhere. For example, it has been shown that resveratrol alone causes a dose-dependent increase in AP activity when administered to a mature osteoblastic cell line (osteoblastic MC3T3-E1 cells) (Mizutani et al. 1998). Further, this effect was blocked by tamoxifen, an estrogen antagonist, suggesting that some of resveratrol's stimulatory actions may be mediated through the estrogen receptor. In relation to this, others have also shown that resveratrol exhibits various degrees of estrogenic effects (Gehm et al. 1997). However, there are other more recent investigations that question whether resveratrol has any significant estrogenic activity at all, so this issue is still open to some debate (Ashby et al. 1999, Lu \& Serrero 1999, Turner et al. 1999) and warrants further investigation. Furthermore, as shown in models similar to the SBMC model, prostaglandins may inhibit osteogenesis (Ogiso et al. 1992). In other studies it has been shown that resveratrol may possess inherent anti-inflammatory properties (Subbaramaiah et al. 1998, 1999). Hence, it is conceivable that resveratrol's apparent stimulatory effects on some aspects of osteogenesis, especially in the SBMC model, could be related to inhibition of prostaglandin synthesis. In a related sense it was also apparent, especially in the SBMC model, that in some cases when lower levels of TCDD were used, resveratrol not only antagonized TCDD effects, but also promoted even higher AP levels than in control. In addition to resveratrol's putative inhibitory effects on prostaglandin synthesis, it is also conceivable that cooperative (i.e. between TCDD and resveratrol) stimulation of cells is occurring. It might also be postulated that resveratrol could be antagonizing environmentally derived aryl hydrocarbons that may already be present (i.e. constitutive) in the serum supplements used for culture, thereby stimulating osteogenic parameters above control levels.

\section{Collagen synthesis (matrix formation)}

Changes in levels of collagen type I were expected to follow the pattern of changes seen in AP activity and, as expected, a trend in this direction was observed in the level of ${ }^{14} \mathrm{C}$-labeled collagen type I in the CPO model treated with both TCDD and resveratrol. However, these effects (i.e. resveratrol antagonism of TCDD effects) were not statistically significant. It is possible that in addition to its ability to inhibit collagen synthesis and mRNA formation TCDD may also have inhibited collagen degradation. This could conceivably allow an accumulation of some collagen over the culture period even with less synthesis, which could partially mask a reduction in newly synthesized collagen levels. Turnover and remodeling of collagen is known to occur continuously during both physiological and pathological conditions and appears to be accomplished through the action of a number of proteolytic enzymes and lysosomal phagocytosis (Everts et al. 1996). In this regard, we have shown previously that collagen phagocytosis, the principal pathway of collagen turnover, is regulated by AP (Hui et al. 1997). As TCDD decreases AP activity and presumably AP protein due to mRNA reductions, it is conceivable that AP-dependent collagen phagocytosis could also be inhibited, thereby decreasing the impact of reductions in synthesis of collagen in the TCDD-treated cultures despite obvious reductions in mRNA for this protein. In any case, the histological observations of the CPO model suggested that bone matrix formation (i.e. related to bone collagen production) is almost certainly reduced by TCDD and then brought back to more normal levels in TCDD/resveratrol-treated cultures.

\section{Mineralization}

TCDD mediated substantial reductions in mineralization as shown by decreases in phosphate and calcium accumulation. Resveratrol antagonized the TCDD-mediated inhibition of mineralization in SBMC cultures and this occurred in a dose-dependent fashion, similar to its effect on TCDD-mediated inhibition of AP activity. However, when the concentration of TCDD exceeded $4.12 \times$ $10^{-11} \mathrm{M}$, resveratrol could not antagonize its effect. Inasmuch as TCDD has the highest binding affinity to the AhR of all known compounds (Rowlands \& Gustafsson 1997), it would appear that resveratrol could not compete with TCDD for the latter's cognate receptor, at these high doses. Interestingly, mineralization in the CPO model was inhibited by TCDD, but only partially (not shown; $P>0.05)$. These findings are difficult to explain, especially in light of the data obtained using the SBMC model. One explanation may be related to the fact that although the rat SBMC line and CPO models produced comparable results they were not always identical. Similarly, the two models are not identical either. For example, whereas the rat SBMC line, like the RBMC model, relies absolutely on the presence of a glucocorticoid such as dexamethasone for osteodifferentiation (Grigoriadis et al. 1988, Maniatopoulos et al. 1988, Kasugai et al. 1991, Shalhoub et al. 1992, 
Rickard et al. 1994, Herbertson \& Aubin 1995), the CPO model does not (McCulloch \&Tenenbaum 1986) suggesting the presence of glucocorticoid-dependent and -independent osteogenic cells. TCDD may not affect the glucocorticoid-independent osteogenic cells in the same manner as the glucocorticoid-dependent ones. That having been said, it is also important to note that BSP mRNA levels were significantly reduced in the CPO model (an effect that was antagonized by resveratrol). BSP is thought to play an important, although perhaps not an exclusive or obligatory role in mineralization (Sodek et al. 1995). This could explain in part how TCDD inhibits some mineralization in the CPO model, while non-BSP-mediated mineralization could still occur.

\section{Conclusions}

The evidence gathered from these experiments supports the hypothesis that TCDD, a prototypical AhR ligand, inhibits bone formation and could explain how similar hydrocarbons may predispose smokers to both osteoporosis and periodontal bone loss. This inhibition appears to be receptor mediated and occurs during cellular proliferation and osteoblastic differentiation. Resveratrol, a novel AhR antagonist, competes for the AhR and partially or fully antagonizes AhR ligand effects depending on the model or parameters being used. The clinical implications of these findings could be important because it is possible that resveratrol may be considered as a therapeutic agent which might protect bone and periodontal tissues from some of the deleterious effects of environmental hydrocarbons in general and cigarette smoking in particular.

\section{Acknowledgements}

The authors wish to thank Dr Sandu Pitaru for supplying them with the SBMC cell line. R F C and H C T were supported by the Medical Research Council of Canada Operating and Group grants respectively, while J F S was supported by INSERM (France).

\section{References}

Abbott BD \& Probst MR 1995 Developmental expression of two members of a new class of transcription factors II: expression of aryl hydrocarbon receptor nuclear translocator in the C57BL/6N mouse embryo. Developmental Dynamics 204 144-155.

Ah MK, Johnson GK, Kaldahl WB, Patil KD \& Kalkwarf KL 1994 The effect of smoking on the response to peridontal therapy. Journal of Clinical Periodontology 21 91-97.

Aloia JF, Cohn SH, Vaswani A, Yeh JK, Yuen K \& Ellis K 1985 Risk factors for postmenopausal osteoporosis. American Journal of Medicine 78 95-100.

Ashby J, Tinwell H, Pennie W, Brooks AN, Lefevre PA, Beresford N \& Sumpter JP 1999 Partial and weak oestrogenicity of the red wine constituent resveratrol: consideration of its superagonist activity in MCF-7 cells and its suggested cardiovascular protective effects. Journal of Applied Toxicology 19 39-45.

Bain CA \& Moy PK 1993 The association between the failure of dental implants and cigarette smoking. International Journal of Oral and Maxillofacial Implants 8 609-615.

Bergstrom J 1989 Cigarette smoking as risk factor in chronic periodontal disease. Community Dentistry and Oral Epidemiology 17 245-247.

Birnbaum LS 1994 Evidence for the role of the Ah receptor in response to dioxin. In Receptor-Mediated Biological Processes: Implications for Evaluating Carcinogens. Progress in Clinical and Biomedical Research, vol 387, pp 139-154. Eds HL Spitzer, TL Slaga, WF Greenlee \& M McClain. New York: Wiley-Liss.

Bjeldanes LF, Kim JY, Grose KR, Bartholomew JC \& Bradfield CA 1991 Aromatic hydrocarbon responsiveness-receptor agonists generated from indole-3-carbinol in vitro and in vivo: comparisons with 2,3,7,8-tetrachlorodibenzo-p-dioxin. PNAS 88 9543-9547.

Casper RF, Quesne M, Rogers IM, Shirota T, Jolivet A, Milgrom E \& Savouret JF 1999 Resveratrol has antagonist activity on the aryl hydrocarbon receptor: implications for prevention of dioxin toxicity. Molecular Pharmacology 56 784-790.

Charles GD \& Shiverick KT 1997 2,3,7,8-Tetrachlorodibenzo-pdioxin increases mRNA levels for interleukin-1 beta, urokinase plasminogen activator, and tumor necrosis factor-alpha in human uterine endometrial adenocarcinoma RL95-2 cells. Biochemical and Biophysical Research Communications 238 338-342.

Ciolino HP, Daschner PJ \& Yeh GC 1998 Resveratrol inhibits transcription of CYP1A1 in vitro by preventing activation of the aryl hydrocarbon receptor. Cancer Research 58 5707-5712.

De Bruyn H \& Collaert B 1994 The effect of smoking on early implant failure. Clinical Oral Implants Research 5 260-264.

Demetriou M, Binkert C, Sukhu B, Tenenbaum HC \& Dennis JW 1996 Fetuin/alpha2-HS glycoprotein is a transforming growth factor-beta type II receptor mimic and cytokine antagonist. Journal of Biological Chemistry 271 12755-12761.

Egger P, Duggleby S, Hobbs R, Fall C \& Cooper C 1996 Cigarette smoking and bone mineral density in the elderly. Journal of Epidemiology and Community Health 50 47-50.

Everts V, van der Zee E, Creemers L \& Beertsen W 1996 Phagocytosis and intracellular digestion of collagen, its role in turnover and remodelling. Histochemical Journal 28 229-245.

Franceschi S, Schinella D, Bidoli E, Dal Maso L, La Vecchia C, Parazzini F \& Zecchin R 1996 The influence of body size, smoking, and diet on bone density in pre- and postmenopausal women. Epidemiology 7 411-414.

Gehm BD, McAndrews JM, Chien PY \& Jameson JL 1997 Resveratrol, a polyphenolic compound found in grapes and wine, is an agonist for the estrogen receptor. PNAS 94 14138-14143.

Genco RJ \& Kinane D 1999 Smoking and periodontitis. Journal of the International Academy of Periodontology 1 21-33.

Gierthy JF, Silkworth JB, Tassinari M, Stein GS \& Lian JB 1994 2,3,7,8-Tetrachlorodibenzo-p-dioxin inhibits differentiation of normal diploid rat osteoblasts in vitro. Journal of Cellular Biochemistry 54 231-238.

Golub EE 1996 Enzymes in mineralizing systems: state of the art. Connective Tissue Research 35 183-188.

Grigoriadis AE, Heersche JN \& Aubin JE 1988 Differentiation of muscle, fat, cartilage, and bone from progenitor cells present in a bone-derived clonal cell population: effect of dexamethasone. Journal of Cellular Biology 106 2139-2151.

Grisso JA, Kelsey JL, O’Brien LA, Miles CG, Sidney S, Maislin G, LaPann K, Moritz D \& Peters B 1997 Risk factors for hip fracture in men. Hip fracture study group. American Journal of Epidemiology $145786-793$.

Haber J \& Kent RL 1992 Cigarette smoking in a periodontal practice. Journal of Periodontology 63 100-106. 
Haber J, Wattles J, Crowley M, Mandell R, Hoshipura K \& Kent RL 1993 Evidence for cigarette smoking as a major risk factor for periodontitis. Journal of Periodontology 64 16-23.

Harper N, Wang X, Liu H \& Safe S 1994 Inhibition of estrogeninduced progesterone receptor in MCF-7 human breast cancer cells by aryl hydrocarbon (Ah) receptor agonists. Molecular and Cellular Endocrinology 104 47-55.

Harris M, Zacharewski T \& Safe S 1990 Effects of 2,3,7,8tetrachlorodibenzo-p-dioxin and related compounds on the occupied nuclear estrogen receptor in MCF-7 human breast cancer cells. Cancer Research 50 3579-3584.

Herbertson A \& Aubin JE 1995 Dexamethasone alters the subpopulation make-up of rat bone marrow stromal cell cultures. Journal of Bone and Mineral Research 10 285-294.

Hollenbach KA, Barrett-Connor E, Edelstein SL \& Holbrook T 1993 Cigarette smoking and bone mineral density in older men and women. American Journal of Public Health 83 1265-1270.

Hopper JL \& Seeman E 1994 The bone density of female twins discordant for tobacco use. New England Journal of Medicine 330 387-392.

Horning GM, Hatch CL \& Cohen ME 1992 Risk indicators for periodontitis in a military treatment population. Journal of Periodontology 63 297-302.

Hui MZ, Tenenbaum HC \& McCulloch CA 1997 Collagen phagocytosis and apoptosis are induced by high level alkaline phosphatase expression in rat fibroblasts. Journal of Cellular Physiology 172 323-333.

Johansson C \& Mellstrom D 1996 An earlier fracture as a risk factor for new fracture and its association with smoking and menopausal age in women. Maturitas 24 97-106.

Kamalia N, McCulloch CA, Tenenbaum HC \& Limeback H 1992 Direct flow cytometric quantification of alkaline phosphatase activity in rat bone marrow stromal cells. Journal of Histochemistry and Cytochemistry 40 1059-1065.

Kasugai S, Todescan R Jr, Nagata T, Yao KL, Butler WT \& Sodek J 1991 Expression of bone matrix proteins associated with mineralized tissue formation by adult rat bone marrow cells in vitro: inductive effects of dexamethasone on the osteoblastic phenotype. Journal of Cellular Physiology 147 111-120.

Kiel DP, Zhang Y, Hannan MT, Anderson JJ, Baron JA \& Felson DT 1996 The effect of smoking at different life stages on bone mineral density in elderly men and women. Osteoporosis International 6 240-248.

Krishnan V, Porter W, Santostefano M, Wang X \& Safe S 1995 Molecular mechanism of inhibition of estrogen-induced cathepsin D gene expression by 2,3,7,8-tetrachlorodibenzo-p-dioxin (TCDD) in MCF-7 cells. Molecular and Cellular Biology 15 6710-6719.

La Vecchia C, Negri E, Levi F \& Baron JA 1991 Cigarette smoking, body mass and other risk factors for fractures of the hip. International Journal of Epidemiology 20 671-677.

Lavin AL, Hahn DJ \& Gasiewicz TA 1998 Expression of functional aromatic hydrocarbon receptor and aromatic hydrocarbon nuclear translocator proteins in murine bone marrow stromal cells. Archives of Biochemistry and Biophysics 352 9-18.

Lekic P, Rubbino I, Krasnoshtein F, Cheifetz S, McCulloch CA \& Tenenbaum H 1997 Bisphosphonate modulates proliferation and differentiation of rat periodontal ligament cells during wound healing. Anatomical Record 247 329-340.

Liu H, Wormke M, Safe SH \& Bjeldanes LF 1994 Indolo[3,2-b] carbazole: a dietary-derived factor that exhibits both antiestrogenic and estrogenic activity [see comments]. Journal of the National Cancer Institute 86 1758-1765.

Lu R \& Serrero G 1999 Resveratrol, a natural product derived from grape, exhibits antiestrogenic activity and inhibits the growth of human breast cancer cells. Journal of Cellular Physiology 179 297-304.
Maniatopoulos C, Sodek J \& Melcher AH 1988 Bone formation in vitro by stromal cells obtained from bone marrow of young adult rats. Cell and Tissue Research 254 317-330.

McCulloch CA \& Tenenbaum HC 1986 Dexamethasone induces proliferation and terminal differentiation of osteogenic cells in tissue culture. Anatomical Record 215 397-402.

McCulloch CA, Strugurescu M, Hughes F, Melcher AH \& Aubin JE 1991 Osteogenic progenitor cells in rat bone marrow stromal populations exhibit self-renewal in culture. Blood 77 1906-1911.

Mizutani K, Ikeda K, Kawai Y \& Yamori Y 1998 Resveratrol stimulates the proliferation and differentiation of osteoblastic MC3T3-E1 cells. Biochemical and Biophysical Research Communications 253 859-863.

Nguyen TV, Kelly PJ, Sambrook PN, Gilbert C, Pocock NA \& Eisman JA 1994 Lifestyle factors and bone density in the elderly: implications for osteoporosis prevention. Journal of Bone and Mineral Research 9 1339-1346.

Nijweide PJ 1975 Embryonic chicken periosteum in tissue culture: osteoid formation and calcium uptake. Proceedings of the Koninklijke Nederlandse Akademie van Wetenschappen. Series C: Biological and Medical Sciences C78 410-417.

Nodland KI, Wormke M \& Safe S 1997 Inhibition of estrogeninduced activity by 2,3,7,8-tetrachlorodibenzo-p-dioxin (TCDD) in the MCF-7 human breast cancer and other cell lines transfected with vitellogenin A2 gene promoter constructs. Archives of Biochemistry and Biophysics 338 67-72.

Ogiso B, Hughes FJ, Davies JE \& McCulloch CA 1992 Fibroblastic regulation of osteoblast function by prostaglandins. Cellular Signalling $4627-639$

Papapanou PN 19961996 World workshop in periodontics: periodontal diseases: epidemiology. Annals of Periodontology 1 1-36.

Pitaru S, Kotev-Emeth S, Noff D, Kaffuler S \& Savion N 1993 Effect of basic fibroblast growth factor on the growth and differentiation of adult stromal bone marrow cells: enhanced development of mineralized bone-like tissue in culture. Journal of Bone and Mineral Research 8 919-929.

Preber H \& Bergstrom J 1990 Effect of cigarette smoking on periodontal healing following surgical therapy. Journal of Clinical Periodontology 17 324-328.

Rickard DJ, Sullivan TA, Shenker BJ, Leboy PS \& Kazhdan I 1994 Induction of rapid osteoblast differentiation in rat bone marrow stromal cell cultures by dexamethasone and BMP-2. Developmental Biology 161 218-228.

Rowlands JC \& Gustafsson J-A 1997 Aryl hydrocarbon receptormediated signal transduction. Critical Reviews in Toxicology 27 109-134.

Safe S \& Krishnan V 1995 Chlorinated hydrocarbons: estrogens and antiestrogens. Toxicology Letters 82-83 731-736.

Safe S, Astroff B, Harris M, Zacharewski T, Dickerson R, Romkes M \& Biegel L 1991 2,3,7,8-Tetrachlorodibenzo-p-dioxin (TCDD) and related compounds as antioestrogens: characterization and mechanism of action. Pharmacology and Toxicology 69 400-409.

Shalhoub V, Conlon D, Tassinari M, Quinn C, Partridge N, Stein GS \& Lian JB 1992 Glucocorticoids promote development of the osteoblast phenotype by selectively modulating expression of cell growth and differentiation associated genes. Journal of Cellular Biochemistry 50 425-440.

Sodek J, Kim RH, Ogata Y, Li J, Yamauchi M, Zhang Q \& Freedman LP 1995 Regulation of bone sialoprotein gene transcription by steroid hormones. Connective Tissue Research $\mathbf{3 2}$ 209-217.

Subbaramaiah K, Chung WJ, Michaluart P, Telang N, Tanabe T, Inoue H, Jang M, Pezzuto JM \& Dannenberg AJ 1998 Resveratrol inhibits cyclooxygenase-2 transcription and activity in phorbol ester-treated human mammary epithelial cells. Journal of Biological Chemistry 273 21875-21882. 
Subbaramaiah K, Michaluart P, Chung WJ, Tanabe T, Telang N \& Dannenberg AJ 1999 Resveratrol inhibits cyclooxygenase-2 transcription in human mammary epithelial cells. Annals of the New York Academy of Sciences 889 214-223.

Sukhu B, Rotenberg B, Binkert C, Kohno H, Zohar R, McCulloch CA \& Tenenbaum HC 1997 Tamoxifen attenuates glucocorticoid actions on bone formation in vitro. Endocrinology 138 3269-3275.

Sutter TR, Guzman K, Dold KM \& Greenlee WF 1991 Targets for dioxin: genes for plasminogen activator inhibitor-2 and interleukin-1 beta. Science 254 415-418.

Tenenbaum HC 1981 Role of organic phosphate in mineralization of bone in vitro. Journal of Dental Research 60 (Spec. No. C) 15861589.

Tenenbaum HC \& Heersche JNM 1982 Differentiation of osteoblasts and formation of mineralized bone in vitro. Calcified Tissue International 34 76-79.

Tenenbaum HC \& Heersche JNM 1985 Dexamethasone stimulates osteogenesis in chick periosteum in vitro. Endocrinology 117 2211-2217.

Tenenbaum HC \& Heersche JNM 1986 Differentiation of osteoidproducing cells in vitro: possible evidence for the requirement of a microenvironment. Calcified Tissue International 38 262-267.

Tenenbaum HC, Palangio KG, Holmyard DP \& Pritzker KPH 1986 An ultrastructural study of osteogenesis in chick periosteum in vitro. Bone 7 295-302.
Tenenbaum HC, McCulloch CAG, Fair C \& Birek C 1989 The regulatory effect of phosphates on bone metabolism in vitro. Cell and Tissue Research 257 555-563.

Tenenbaum HC, Kamalia N, Sukhu B, Limeback H \& McCulloch CA 1995 Probing glucocorticoid-dependent osteogenesis in rat and chick cells in vitro by specific blockade of osteoblastic differentiation with progesterone and RU38486. Anatomical Record 242 200-210.

Termine JD 1993 Bone matrix proteins and the mineralization process. In Primer on the Metabolic Bone Diseases and Disorders of Mineral Metabolism, pp 21-25. Ed. MJ Favus. New York: Raven Press.

Turner RT, Evans GL, Zhang M, Maran A \& Sibonga JD 1999 Is resveratrol an estrogen agonist in growing rats? Endocrinology 140 $50-54$.

Wang X, Porter W, Krishnan V, Narasimhan TR \& Safe S 1993 Mechanism of 2,3,7,8-tetrachlorodibenzo-p-dioxin (TCDD)-mediated decrease of the nuclear estrogen receptor in MCF-7 human breast cancer cells. Molecular and Cellular Endocrinology 96 159-166.

Williams AR, Weiss LG \& Ure CL 1982 Effect of weight, smoking and estrogen use on the risk of hip and forearm fractures in postmenopausal women. Obstetrics and Gynecology 60 695-699.

Received 27 February 2000

Accepted 15 June 2000 